\title{
CRESCIMENTO DO ENSINO SUPERIOR E POPULARIZAÇÃO DO ACESSO: NECESSIDADE DE UMA NOVA METODOLOGIA DE ENSINO?
}

\section{GROWTH OF HIGHER EDUCATION AND ACCESS POPULARIZATION: NEED FOR A NEW TEACHING METHODS?}

\author{
${ }^{1}$ Jailsom Leandro de Sousa
}

\section{RESUMO}

O presente artigo trata do crescimento dos cursos e das matrículas no ensino superior no Brasil - e do curso de Direito em particular - e a mudança no perfil dos alunos ingressantes, notadamente pela adoção das políticas de cotas e pelo financiamento público de vagas em instituições privadas. Considerando as dificuldades desses alunos, procura responder se a metodologia de ensino superior existente é adequada ou se seria necessário criar uma nova para atendê-los. Com o intuito de assegurar a qualidade no ensino e de propiciar aos ingressos condições de realizar seu potencial, relaciona medidas a serem tomadas.

Palavras-chave: Ensino superior, Crescimento, Acesso, Cotas, Curso de direito, Metodologia

\begin{abstract}
This article deals with the growth of courses and enrollment in higher education in Brazil and in particular law school - and the change in the profile of the new students, especially the adoption of quota policies and public funding of places in private institutions . Considering the difficulties of these students, seeks to respond to the existing higher education methodology is appropriate or whether it would be necessary to create a new one to serve them. In order to ensure quality in education and to provide the tickets conditions to realize their potential, related measures to be taken.
\end{abstract}

Keywords: Higher education, Growth, Access, Quotas, Law course, Methodology

\footnotetext{
${ }^{1}$ Mestrando em Direito na Universidade Federal de Sergipe - UFS, São Cristóvão, Sergipe (Brasil).

E-mail: jailsom.sousa@hotmail.com
} 


\section{INTRODUÇÃO}

O presente artigo aborda aspecto relevante da realidade do ensino superior no Brasil na segunda década do século XXI, consistente na massificação do acesso aos cursos superiores em decorrência de políticas implementadas nas duas últimas décadas. Uma realidade que mudou a cara da universidade, dando-lhe uma aparência mais condizente com a pluralidade da sociedade brasileira.

Mais que nunca, a diversidade chegou à universidade: são alunos de todas as origens, de todas as raças, de todas as rendas, de variadas faixas etárias, de escolas públicas e de escolas privadas. E, junto com a aparência diferente, plural, que retrata bem a diversidade e a complexidade brasileiras, trouxe àquela instituição até então da elite o desafio de continuar sendo uma instituição de elite. Explica-se. De elite não pela origem daqueles que acolhe ou que a dirigem (não se ignora que o corpo funcional seja basicamente de classe média), mas pela qualidade do trabalho e do conhecimento nela produzidos, e por sua capacidade de continuar contribuindo de maneira positiva e decisiva para a formação intelectual da sociedade.

Não obstante sua posição, a universidade - termo utilizado aqui de forma a técnica para definir o conjunto de todas as entidades de ensino superior, posto que compostas também por centros universitários, faculdades e institutos federais - sempre teve suas dificuldades, mesmo nos tempos de prevalência de homogeneidade social.

O desafio de continuar a ser uma instituição com produção de qualidade traz consigo a dúvida sobre se há necessidade de criação de uma nova metodologia do ensino superior, ou se o conhecimento já existente dá conta do ensino para esse conjunto diversificado e diferente.

Buscando resposta a essa pergunta, utilizou-se como referencial a realidade dos cursos de Direito, dada a conveniência de associar a análise a um curso específico, em vez de teorizar abstratamente. As colocações feitas poderão certamente ser compreendidas de forma extensiva.

A metodologia de pesquisa utilizada foi a pesquisa bibliográfica a livros, dissertações de mestrado e trabalhos de conclusão de curso. Utilizou-se, também, pesquisa direta aos dados estatísticos do Instituto Nacional de Estudos e Pesquisas Educacionais Anísio Teixeira (INEP). 
O trabalho foi desenvolvimento em três partes. Na primeira, abordou-se a expansão do acesso ao ensino superior e ao curso de Direito no Brasil. Ato contínuo, tratou-se do perfil atual dos alunos que chegam ao ensino superior e, em seguida, abordouse o desafio de educar esses alunos, discutindo a adequação da metodologia. Ao final, apresentaram-se algumas conclusões.

\section{A POPULARIZAÇÃO ACESSO AO ENSINO SUPERIOR NO BRASIL}

Umberto Eco, em seu clássico Como Se Faz Uma Tese, publicado originalmente em 1977, narra que a Itália de então vivia uma situação de massificação ou popularização [termos não utilizados por ele] do acesso ao ensino superior, com matrículas de milhões de estudantes, muitos deles com sérias deficiências educacionais precedentes e necessitando conciliar o estudo com o trabalho.

Inquieto com a situação, o professor escreveu aquele livro com o intuito de auxiliar esses a alunos a escreverem suas teses de conclusão de graduação.

Quarenta anos depois, o Brasil aparentemente vive situação similar de massificação do acesso ao ensino superior. Enfrenta problemas semelhantes aos que Eco identificou em sua Itália e que o levou a dedicar empenho na redação daquela obra extremamente útil, desde então, a estudantes de vários continentes.

Porém, questiona-se inicialmente se o país de fato vive uma situação de acesso em massa de pessoas ao ensino superior. A resposta a esta pergunta exige pesquisa à fonte direta.

Consultando o sítio do INEP, que é a autarquia do Ministério da Educação responsável pelos estudos e pesquisas educacionais, encontram-se dados que poderão contribuir para a resposta. Mostram-se alguns na tabela 01 a seguir, referente ao número de cursos superioresde graduação no período de 1991 a 2010. Veja-se: 


\begin{tabular}{|l|l|l|l|l|}
\hline Natureza da IES & 1991 & 1995 & 2003 & 2010 \\
\hline Total & 4.908 & 6.253 & 16.453 & 28.577 \\
\hline Públicas & 2.139 & 2.783 & 5.662 & 8.821 \\
\hline (Federais) & $(1.143)$ & $(1.536)$ & $(2.392)$ & $(5.024)$ \\
\hline Privadas & 2.769 & 3.470 & 10.791 & 19.756 \\
\hline
\end{tabular}

Tabela 1 - Cursos de Graduação Presenciais

Elaborada pelo Autor. Fonte: INEP

Conforme se observa, em 1991, o número total era de 4.908 cursos e, em 2010, de 28.577, o que representa um crescimento de 482,25\%. Analisando sob o aspecto da natureza da instituição de ensino superior (IES), tem-se que nesse mesmo período os cursos da rede privada passaram de 2.769 para 19.756 , um crescimento equivalente a $613,47 \%$. Os da rede pública foram de 2.139 para 8.821 , variação correspondente a 312,39\%.

Se filtrado da rede pública a rede federal, notar-se-á que o crescimento desta no período foi de 1.143 para 5.024 cursos, ou 339,54\%. Uma variação de 3.881 cursos, sendo destes 1.249 no período 1991-2003 e 2.632 no período 2003-2010.

Verifica-se, então, que no período de 19 anos o país praticamente sextuplicou o número de cursos de graduação e que este crescimento ocorreu majoritariamente na rede privada de ensino, no percentual de $613,47 \%$, ou seja, no segmento privado o crescimento superou a multiplicação por sete. O ensino superior público também cresceu, multiplicando o número de vagas aproximadamente por quatro, sendo um pouco superior o crescimento na rede federal, correspondente a $339,54 \%$ ou 3.881 , dos quais $32,18 \%$ dele entre $1991-2013$ e $67,81 \%$ no período 2003-2010. Cabe checar se o aumento do número de matrículas guardou correspondente crescimento.

A tabela 02 a seguir mostra a evolução do número de matrículas em cursos de graduação entre 1991 e 2010. 


\begin{tabular}{|l|l|l|l|l|}
\hline & 1991 & 1995 & 2003 & 2010 \\
\hline Total & 1.565 .056 & 1.759 .703 & 3.887 .022 & 5.449 .120 \\
\hline Públicas & 605.736 & 700.540 & 1.136 .370 & 1.461 .696 \\
\hline (Federais) & $(320.135)$ & $(357.531)$ & $(567.101)$ & $(833.934)$ \\
\hline Privadas & 959.320 & 1.059 .163 & 2.750 .652 & 3.987 .424 \\
\hline
\end{tabular}

Tabela 2 - Número de Matrículas em Cursos de Graduação

Elaborada pelo Autor. Fonte: INEP

Em 1991, o número total era 1.565.056 matriculas e, em 2010, 5.449.120, o que representa um crescimento de $248,17 \%$.

Nesse mesmo período, as matrículas na rede privada passaram de 959.320 para 3.987.424, um crescimento equivalente a $315,65 \%$.

As da rede pública passaram de 605.736 para 1.461 .696 , variação correspondente a $141,31 \%$.

Se analisado apenas o crescimento na rede federal, o crescimento no período foi de 320.135 matrículas para 833.934, ou 160,49\%. Assim, a variação do número na rede federal foi de 513.799 matrículas.

Registre-se que a variação populacional foi de $29,91 \%$ (vinte e nove inteiros e noventa e um centésimos por cento). Segundo o Instituto Brasileiro de Geografia e Estatística - IBGE, a população brasileira em 1991 era 146.825.475 habitantes e, em 2010, 190.747.855 habitantes.

Nota-se, analisando a tabela, que no período 1991-2010 o número de matrículas em cursos de graduação multiplicou por 3,5 e que o crescimento foi ainda maior na rede privada de ensino, onde o crescimento equivaleu a uma multiplicação por 4,26.

Evidentemente, o crescimento do número de matrículas no período 1991-2010 $(248,17 \%)$ superou o crescimento populacional $(29,91 \%)$, o que é natural e desejável, sem que se possa afirmar que esse crescimento tenha sido suficiente, haja vista o histórico déficit de investimento em educação e em especial no ensino superior. 


\subsection{0 crescimento dos cursos de Direito}

Os primeiros cursos de Direito no Brasil foram criados em 1827 nas cidades de Olinda e São Paulo e tinham por objetivo qualificar a elite local para ocupar os cargos de direção do Estado em seus vários segmentos, dispensando-a de ter que necessariamente ir à Metrópole para graduar-se em Direito (Ciências Jurídicas e Sociais).

Analisando o número de cursos de Direito existentes nos anos de 2003 e 2013, obtiveram-se os seguintes dados:

\begin{tabular}{|l|l|l|}
\hline DIREITO & 2003 & \multicolumn{2}{|l|}{2013} \\
\hline Cursos & 704 & $\mathbf{1 . 1 4 9}$ \\
Cursos Privadas & 591 & $\mathbf{9 6 7}$ \\
Vagas Oferecidas & 197.988 & $\mathbf{2 2 0 . 7 9 9}$ \\
Ingresso & 140.416 & $\mathbf{2 3 7 . 5 3 0}$ \\
Concluintes Total & 64.413 & $\mathbf{9 5 . 1 1 8}$ \\
Concluintes Privadas & 53.890 & 81.903 \\
\hline
\end{tabular}

Tabela 03 - Direito: Cursos, Oferta, Ingresso e Concluintes.

Elaborada pelo Autor. Fonte: INEP

Percebe-se que os números de cursos, vagas oferecidas, alunos ingressantes e concluintes já eram grandes em 2003 e cresceram mais ainda no período. O número de cursos aumentou $63,20 \%$, passando de 704 para 1.149, sendo um pouco maior o aumento relativo às entidades privadas, os quais passando de 591 para 967, correspondente a 63,62\%.

O número de ingressantes cresceu 69,16\% (indo de 140.416 para 237.530) e o número de concluintes variou de 64.413 para 95.118 , ou $47,67 \%$.

Dois pontos da tabela requerem esclarecimentos.

O primeiro, o porquê de em 2013 ter ingressado mais alunos que o número de vagas oferecidas, ao que se justifica com a notícia de que o número de ingressantes considera também pessoas que se valeram de outras formas de acesso que não apenas o vestibular. 
O segundo, a razão pela qual, em 1993, o número de ingressantes ter sido bem menor que o de vagas oferecidas, enquanto em 2013 o número de ingressantes superou o de vagas oferecidas.

A explicação encontra-se no fato de em 2013 parte das vagas dos cursos de graduação privados terem sido compradas pelo Governo Federal por meio do Programa Universidade para Todos (PROUNI), para distribuição a alunos de baixa renda com isenção total ou parcial, ou terem sido financiadas pelo Fundo de Financiamento ao Estudante do Ensino Superior (FIES), tendo sido ocupadas, portanto, mais do que a totalidade das vagas oferecidas.

A transferência de recursos públicos para as faculdades privadas por meio dessas duas fontes resultou na mudança de um quadro de ociosidade de $29,08 \%$ das vagas oferecidas (2003) para um quadro superavitário em 2013, ano no qual se ocupou todas as vagas oferecidas no vestibular e mais $7,58 \%$.

Conclui-se, pois, indo além do curso de Direito, que de fato houve uma grande expansão no acesso ao ensino superior no Brasil nas duas últimas décadas, podendo-se falar numa popularização do acesso ao ensino superior, tamanho o crescimento do número de vagas e a facilitação para ingresso de seguimentos sociais antes excluídos. E também que essa expansão deu-se principalmente pelo incentivo à iniciativa privada, em um primeiro momento mediante a autorização para a abertura de cursos, elegendo a iniciativa privada como meio preferencial para a expansão do ensino superior, e em um segundo momento pelo financiamento público de parte de suas vagas, seja pela compra mediante compensação tributária para oferta a alunos carentes, seja pela concessão de financiamento aos alunos pelo programa de financiamento estudantil.

\section{O PERFIL DOS ALUNOS DO ENSINO SUPERIOR E A REALIDADE DO ENSINO DE DIREITO}

A popularização do acesso aos cursos superiores no Brasil trouxe aos bancos escolares um perfil diferente de estudante, o que pode ser visto em dois instantes distintos, conforme se considere as instituições de ensino superior privadas ou públicas.

Estimuladas pelo Estado a partir dos anos 1990, as instituições privadas de ensino superior aproveitaram a oportunidade de negócio decorrente da opção feita pelo Estado de oferta de poucas vagas pelas instituições públicas. 
As vagas das instituições públicas eram ocupadas geralmente por aqueles que tiveram condições de frequentar escolas particulares no primeiro e segundo graus e com isso obterem as maiores notas para conquistar as vagas oferecidas nos vestibulares. A exigência de cursar escolas particulares acabava por selecionar aqueles que detinham as melhores rendas.

Em suma, as faculdades privadas eram a opção que restava aos que não conseguiam aprovação no vestibular ou para aqueles que necessitavam trabalhar para se manter durante o curso superior.

Consumava-se o paradoxo de a universidade pública ser destinada para os alunos de melhores condições que podiam pagar os estudos, e que já haviam pago os graus antecedentes, enquanto para as faculdades privadas iam exatamente os alunos que tinham renda baixa e haviam cursado o ensino público.

Não bastasse, pode-se afirmar que a rede privada se expandiu porque enxergou e aproveitou a excelente oportunidade de negócio, na qual, no mais das vezes, era possível lucrar muito instalando variados cursos de baixo custo e geralmente de baixa qualidade, vis à vis a ausência de fiscalização estatal efetiva.

A expansão da rede pública foi mais lenta, tendo se destacado mais a partir da primeira década deste século.

Ocorreu por meio de várias iniciativas, podendo-se citar como exemplos o aumento de vagas em cursos já existentes e a abertura de novos cursos com prioridade para o período noturno; a criação de novas universidades ou de novos campi em universidades já existentes, com prioridade para a interiorização; e o investimento no ensino à distância por meio da criação da Universidade Aberta do Brasil (UAB), consórcio que envolve várias universidades públicas para a prestação de cursos de graduação e de pós-graduação na modalidade semipresencial, ambos não alcançados nos quantitativos aqui referidos.

Não obstante a expressiva expansão nas universidades públicas, nas quais o número de vagas nos últimos dezenove anos quase quadruplicou, não se pode afirmar que a popularização do acesso a elas tenha ocorrido pelo simples aumento do número de vagas. Não foi.

A popularização decorreu principalmente do aumento da proporção das vagas destinadas a alunos oriundos da rede pública de ensino, por meio da chamada política de cotas. 
Políticas afirmativas que asseguram número mínimo de vagas para determinados segmentos sociais têm sido aplicadas há muitos anos em várias universidades públicas brasileiras, federais e estaduais. A título de exemplos, o Estado do Rio de Janeiro promulgou a Lei $\mathrm{n}^{\mathrm{o}} 3.524 / 2000$, reservando $50 \%$ das vagas das universidades do Estado para alunos das redes pública estadual e municipais e a Universidade de Brasília foi a primeira universidade federal a implantar política de cotas, no ano de 2004 (MACEDO, 2009).

Foi a Lei $\mathrm{n}^{\mathrm{o}}$ 12.711/2012, porém, que instituiu um marco sobre o tema, ao instituir política de cotas de caráter geral para todas as universidades federais e institutos federais, destinando $50 \%$ das vagas de todos os cursos para o sistema de cotas, percentual a ser alcançado progressivamente em quatro anos $(12,5 \%, 25 \%, 37,5 \%$ e $50 \%)$.

A opção do legislador foi de fixar cotas em primeiro lugar para os alunos da escola pública, de maneira que todas as vagas seriam destinadas a alunos que tivessem cursado todo o Ensino Médio em escola pública.

Em segundo lugar, optou por cotas econômicas, de forma que metade de todas as vagas seria destinada a alunos com renda familiar inferior a um salário-mínimo e meio e a outra metade para famílias com renda superior a esse patamar.

Em terceiro lugar, cotas raciais e étnicas, de forma que, em cada um desses dois segmentos econômicos, será destinado o percentual igual a soma de pretos, pardos e indígenas identificados no Estado pelo último censo demográfico feito pelo Instituto Brasileiro de Geografia e Estatística (IBGE).

O PROUNI também utiliza o critério étnico e racial de cotas, reservando o número equivalente ao percentual de pretos, pardos e indígenas apurado no último censo.

A adoção do sistema de cotas definido na Lei 12.711/2012 está em fase de implantação (os $50 \%$ de vagas serão atingidos em 2016), mas já é possível perceber a mudança determinante que tem feito no ambiente universitário, principalmente nas instituições federais de ensino superior.

Uma delas é o ingresso de alunos oriundos de escolas públicas em pelo menos metade das vagas, revertendo a realidade segundo a qual só praticamente quem pagava escola particular no Ensino Fundamental e Médio tinha acesso a faculdade pública gratuita, notadamente nos cursos mais concorridos. Enquanto os alunos de escolas públicas, quando conseguiam ingressar, eram relegados aos cursos de carreiras menos prestigiadas. Com a 
mudança, alunos de escolas públicas passaram a ter perspectivas concretas de ocupar vagas em todos os cursos, inclusive os mais procurados como o de Medicina.

Essa mudança trará para as faculdades públicas os hábitos e problemas comuns a muitas escolas públicas de ensino médio, como por exemplo a falta de disciplina, a falta de rigor nas atividades e a não conservação do patrimônio público, exigindo a médio prazo o tratamento dessas questões.

Outra mudança consiste em trazer para a universidade pública, inclusive para os cursos mais concorridos, alunos de baixa renda que vivenciam uma realidade social desconhecida pela academia. Um estrato social que nunca esteve presente e que nunca foi participante na definição das questões e prioridades da universidade. Levará a esse espaço, portanto, uma outra visão da sociedade, a do segmento que da classe mais baixa, o que possivelmente enriquecerá a produção universitária pela agregação do ponto de vista de um segmento social que era até agora apenas objeto de estudo, quando muito, e não agente.

Outra perspectiva de mudança é a presença, nas condições citadas, de pessoas de pele preta ou parda e de indígenas em número, dentro da cota de cinquenta por cento, na proporção da soma da participação desses segmentos no Estado, segundo o censo realizado pelo IBGE.

Essa medida, além de propiciar a presença destes segmentos, garantindo que a multiplicidade étnica brasileira esteja presente na universidade, que seja agente nas definições da universidade e protagonistas sociais com maior visibilidade após a conclusão do curso, atenua a tendência histórica de exclusão desses segmentos, ocorrida desde sempre com os indígenas e, com relação aos afrodescendentes, desde a chegada dos africanos escravizados ao Brasil.

Assim, tem-se que o processo de popularização do acesso ao ensino superior na rede pública se deu por um conjunto de ações que visaram aumentar o número de vagas, por um lado, e por outro a instituição de que metade do total das vagas seriam destinadas a alunos oriundos da escola pública, promovendo ainda, entre entes, percentuais mínimos para ingresso de pessoas de baixíssima renda (renda familiar de até 1,5 salário-mínimo) e ou de cor preta, parda ou de origem indígena.

Essas políticas aumentaram a presença na universidade de pessoas de origem afrodescendentes e indígenas e de pessoas de baixa renda, além de assegurar que pelo menos metade das vagas de curso superior nas instituições federais seriam ocupadas por alunos oriundos de escolas públicas. 
Convém não esquecer que a política de cotas também é utilizada para ingresso em cursos de instituições de ensino superior privado, de forma que também nelas aumentou significativamente a presença de pessoas com o perfil eleito na Lei 12.711/12. São alunos, portanto, que, embora tenham, em regra, grande potencial, possuem dificuldades de natureza econômica e de base educacional, dada a baixa qualidade do ensino que obtiveram nas escolas públicas.

Conquanto a qualidade dos alunos em cada curso varie ainda segundo a concorrência, pode-se afirmar que o novo perfil do alunado tem em regra as características acima.

Inclusive no curso de Direito e nas instituições privadas de ensino. Nestas, o perfil há muito se aproxima do descrito acima, tendo em vista que as faculdades privadas sempre acolheram a demanda não satisfeita pelas instituições de ensino públicas. Mesmo assim, se acentuará nas instituições privadas, em face das bolsas do PROUNI e da adoção da lei de cotas na distribuição de parte delas.

\subsection{A realidade dos cursos de Direito}

No que diz respeito ao curso de Direito especificamente, Conceição (2014, pág. 14) relata que ele padece de três problemas.

A descontextualização, pois é ensinado sem discussão sobre a realidade atual, seus problemas, a importância do Direito nesse contexto e a possibilidade de ele contribuir para a solução dos problemas sociais atuais. Em suma, não são feitas reflexões sobre a função social do Direito e a possibilidade de sua utilização para transformação da situação social. Os alunos não desenvolvem, pois, um senso crítico e criativo, tornando-se meros reprodutores das estruturas sociais e jurídicas. Essa realidade é a mesma desde a criação dos primeiros cursos jurídicos em 1827.

O dogmatismo, consistente na apresentação dos conceitos jurídicos como entidades estáticas não passíveis de questionamento e discussão, à semelhança do discurso religioso. Confronta com o entendimento, numa visão atual, de que o Direito é um subsistema do Sistema Social, no qual interage com outros subsistemas, como o Político, o Econômico, a Moral, etc (AGRA, 2013, pág.335).

Nessa visão sistêmica, o Direito não pode se isolar, não obstante seja compreensível que tenha sua linguagem própria e que converta os influxos externos para 
sua linguagem para, então, operar sua atualização interna. Essa atualização precisa ocorrer e o Direito não pode fechar-se inteiramente, sob pena de deixando de cumprir a sua função social ser substituído por outro sistema. O dogmatismo, nessa perspectiva, é a negação do direito enquanto sistema e da necessidade de interlocução dele com a realidade. É o fechamento, a resistência à atualização, ao questionamento que conduz à evolução.

O outro aspecto é a unidisciplinaridade, que, de certa forma, tem relação com o exposto. Diz respeito ao vício de o Direito ser ensinado como uma disciplina isolada, única, ignorando todos os outros saberes. Desconhecendo que a realidade social é complexa e que a solução de seus problemas exige uma abordagem multidisciplinar, englobando conteúdos de ramos diferentes do conhecimento. Ele não pode ignorar a Economia, a História, a Política. Oaluno precisa ser ensinado a refletir o Direito levando em conta sua inter-relação com o conhecimento produzido pelas diversas ciências. O conhecimento é uno, é global e interligado.

A junção desses três problemas citados resultam em um curso que tem formado tecnocratas, pessoas despossuídas de formação humanística e incapazes de senso crítico transformador do Direito, desvinculados de compromisso social e incapazes de questionarem como transformar o Direito para corrigir as injustiças e desigualdades sociais.

Merece registro, para não incidir em omissão, o relativamente pequeno espaço de questionamento surgido no ensino do Direito Constitucional, em especial no ensino dos princípios, da hermenêutica constitucional e dos direitos fundamentais. A discussão desses temas e sua aplicação prática podem constituir embriões para um Direito que questione o status quo e produza significativas mudanças.

O ensino do Direito, porém, está em crise e precisa ser repensado.

Cresceu indiscriminadamente, como visto, e sem observar critérios de qualidade. O critério para o crescimento resumiu-se ao binômio oferta e procura, conjugando o interesse do empresário e a busca do mercado consumidor. Ao empresário o curso jurídico sempre foi muito conveniente, pois atrai muitos interessados e não exige grandes investimentos. Não exige laboratórios e permite montar grandes turmas. Só recentemente o Ministério da Educação passou a exigir titulação acadêmica dos professores, número mínimo de livros nas bibliotecas e a avaliações dos cursos com maior critério.

Do lado do estudante-consumidor, contingentes cada vez maiores de pessoas interessadas na formação jurídica, visualizando o curso como oportunidade de ascensão 
social e de ganhos maiores, notadamente por meio de obtenção de emprego nos altos cargos da burocracia ou pelo exercício da advogacia. Como resultado, tem-se a formação de inúmeras pessoas que não são absorvidas pelo mercado, dados o limitado número de vagas nos concursos e a barreira do exame da Ordem dos Advogados.

Por outro lado, a realidade didática é pobre, centrada no formalismo e na memorização de conceitos e textos legais. As aulas geralmente são monologadas, em que um professor esforça-se com um microfone para prender a atenção do auditório, com pouca participação e poucos debates. Um contexto no qual perde o professor, dado o seu trabalho extenuante e pouco produtivo; perde o aluno, cujo potencial não é aproveitado e que passa a focar na simples reprodução e memorização para obtenção de notas e, por fim, do diploma; e perde a sociedade, já que o ensino deficiente e sem reflexão formará cidadãos passivos e profissionais ineptos, sem brilho e inventividade.

\section{O DESAFIO DE EDUCAR NO CONTEXTO DE POPULARIZAÇÃO DO ACESSO AOS CURSOS SUPERIORES}

É muito grande o desafio de ensinar nesse contexto de ensino superior - e de ensino jurídico. Surge automaticamente como dúvida saber se o conhecimento de metodologia de ensino existente dá conta da tarefa, ou se é necessária a construção de uma nova didática.

A resposta a esta pergunta necessita de uma visualização sobre o conhecimento existente de metodologia do ensino superior, a começar relembrando quais fatores influenciam na aprendizagem.

\subsection{Os fatores que influenciam na aprendizagem}

Gil (2009, p. 58) aponta alguns fatores determinantes para a aprendizagem. A herança genética do aluno, a educação por ele recebida, sua bagagem cultural e suas condições de vida têm grande importância. Pois, a contrario sensu, sabe-se que terão dificuldades de aprendizado alunos que tenham nascido com limitações na capacidade de entendimento, articulação e memorização; alunos que não tenham recebido educação precedente ou que a tenham recebido deficitária, principalmente no quesito técnicas de estudos. Condições de vida também influenciam, pois o aluno que não se alimenta ou que 
tenha que se preocupar com o trabalho e a manutenção da família notoriamente terá mais dificuldades, dada a divisão de atenção. A bagagem cultural também influencia no aprendizado, pois esta permitirá ao aluno uma visão mais ou menos ampla sobre o ensinado, as implicações e as possibilidades decorrentes do conteúdo ministrado.

Outros elementos são a motivação, as razões que o levam a procurar o curso, o que tem a ver com seus projetos pessoais; a concentração do aluno e sua capacidade de reação, esta compreendida como sua manifestação diante do conteúdo ministrado, após a necessária elaboração interna.

A reação é muito importante, pois somente se houver reflexão interna e questionamento poderá de fato haver aprendizado. Caso contrário, o que se tem é a recepção passiva, simples memorização que não prepara para o enfrentamento de situações novas e que não transforma o aluno. Simples absorção de técnicas a serem aplicadas autonomamente, para obtenção de resultados previamente estabelecidos, sem nenhum potencial de mudar a sociedade e o aplicador.

Santos (2001, p. 127), por sua vez, aduz que o advento de novas tecnologias produziu uma mudança no mundo da educação.

Afirma que o acesso ao conhecimento, antes limitado, passou a ser ilimitado, dada a multiplicidade de fontes e a facilidade de se chegar a elas com a utilização da internet e dos meios digitais, inclusive com um vertiginoso barateamento, dada a possibilidade de compartilhamento de materiais. $O$ professor deixou de ser um especialista na matéria ensinada, pois o conhecimento evolui tão rápido que é impossível alguém saber quase tudo, para se tornar um facilitador, a pessoa que media o acesso dos alunos ao conhecimento, indicando as fontes iniciais e problematizando questões para o aluno procurar respostas. $\mathrm{O}$ discente deixou de ser um receptor passivo, sentado diante de um preletor, passando a ser, ou precisando ser, um colaborador ativo, uma pessoa que participa ativamente do processo de aprendizagem, buscando conhecimentos e compartilhando para discussões com a turma.

Além disso, a disponibilização de informações de fácil contato a qualquer um e a qualquer momento, bem como a necessidade de avaliação das fontes, implicou na substituição da ênfase na memorização de fatos para o a adoção do pensamento crítico, capaz não só de construir conhecimento a partir do já existente, mas também de selecionar quais as informações confiáveis no universo infinito de fontes. 
Nesse contexto, o método de ensino deixou de ser o de mera repetição, passando para um método de interação, mais rico e mais envolvente para o aluno. A avaliação também mudou, pois nessa realidade não há sentido em apenas verificar-se a capacidade de o aluno repetir o que foi dito, sendo mais importante extrair qual interpretação ele construiu a partir dos conhecimentos com os quais teve contato.

Vê-se, pois, que o advento das tecnologias implicou em mudanças radicais na educação, propiciando a possibilidade de um aprendizado mais crítico e mais emancipador, posto que o aluno educado conforme as diretrizes apontadas terá mais autonomia e portanto maiores condições de ser livre.

Gil (2009, p. 52), discorrendo sobre o planejamento do ensino, chama a atenção para que os conteúdos sejam definidos conforme os objetivos. Vale dizer, primeiro se deve definir com clareza os objetivos para só depois escolher os conteúdos a serem ministrados. A existência de um juízo criterioso e crítico na definição dos objetivos e do conteúdo possibilitará aulas mais interessantes e oportunidade para discussões mais ricas.

Outra questão é a opção por focar na aprendizagem. O professor não deve se ver como o centro do processo de ensino, o sábio, o único detentor do conhecimento. Pelo contrário, em vez de centrar no ensino, deve centrar na aprendizagem. Considerar que todos são capazes de aprender e de ensinar e todos têm capacidade de, indo às fontes e aplicando os seus conhecimentos e experiências pretéritas, refletir e produzir conhecimento.

O professor é um mediador, alguém que deve auxiliar o aluno no processo de aprendizagem, facilitando o seu contato com as fontes, instigando sua reflexão, fomentando debates e questionamentos.

Além disso, mais que quantidade, deve priorizar a qualidade na definição dos temas e escolha do material indicado para início do processo de pesquisa e buscar aferir o progresso efetivo de cada aluno, sua evolução pessoal, aquilo que o discente for capaz de produzir a partir de sua reflexão.

Há de se atentar, ainda segundo Gil (2009, p. 54), para a necessidade de seleção dos conteúdos conforme a capacidade intelectual dos alunos, seus interesses e necessidades.

A consideração do interesse do aluno e de suas necessidades na definição do conteúdo produz como resultado imediato a percepção de utilidade, despertando a atenção do aluno, aumentando sua motivação e a fixação de conteúdos. Logo, potencializa o aprendizado. 
O interesse do estudante deve ser considerado também na escolha da metodologia, como, por exemplo, a opção por estudo de casos práticos e simulações.

A utilização de casos práticos pode se dar de duas maneiras. Uma, através da aplicação a casos hipotéticos da teoria aprendida em aulas tradicionais. Outra, através do aprendizado da teoria já a partir de casos práticos. Nesta situação, o professor apresenta a situação problema e os alunos vão construir a solução valendo-se inclusive da descoberta, por eles, por meio de pesquisa, das teorias passíveis ou não de aplicação na espécie. Essa possibilidade é a mais rica, formando profissionais mais independentes e capazes, plenamente dominadores da capacidade de aprender, valor de suma importância no mundo atual de constantes transformações que exige o aprendizado contínuo.

Pessoa e Andrade (2013, p. 499) chamam a atenção para a necessidade de os cursos de Direito conciliarem teoria e prática, segundo determinação constante das diretrizes curriculares nacionais dos cursos de graduação em Direito instituídas pela Resolução no 9/2014, do Conselho Nacional de Educação. Afirmam que as características do neoconstitucionalismo irão influenciar o ensino do Direito e propõem um “estudo jurídico focado em casos práticos, dinâmico, fazendo com que o ensino jurídico acompanhe as modificações do sistema como um todo, permitindo a correção de suas imperfeições, em evolução vívida e constante” (pág. 506), propondo, em síntese, a adoção do método baseado em problemas ("Problem Based Learning”- PBL), o qual acreditam que será o preponderante no futuro, inclusive no curso de Direito (p. 506).

De igual forma, tendo em vista que o aprendizado será mais eficiente se for levado em conta as experiências pessoais do aluno, é importante que o docente tenha a iniciativa de conhecer o aluno e seu contexto social para poder levar em conta essa realidade na seleção de conteúdos. Entre dois ou três conteúdos possíveis, selecionar aquele relacionado com a história, o meio ou as características pessoais do discente resultará em uma aula com maior significado para este, o que maximiza sua atenção e a retenção do conteúdo.

Rocha (2007, p. 187) vai além. Após chamar a atenção para a necessidade de um ensino focado na aprendizagem, esse autor recomenda a prática constante da discussão em sala de aula.

Sobre discussão, é importante gerar um espaço de liberdade e respeito recíproco entre todos os participantes de forma a progressivamente levar os mais tímidos à participação. Importante ouvir cada um, respeitar seus posicionamentos e habituá-los ao 
debate, à discordância, ao contraditório, posturas estas necessárias e ao mesmo tempo enriquecedoras para a academia e para a vida.

Na mesma obra (ROCHA, 2007, p. 192) o citado autor inova ao discorrer que o educador deve fomentar o aprendizado dos direitos humanos e da ética, preocupando-se com esta já no ambiente da academia, tanto no proceder de professores como de alunos. Ambos os temas devem ser tratados não de forma isolada, mas com um enfoque inter e transdisciplinar. Vale dizer, devem ser inseridos como assunto transverso, abordando-os de maneira lateral, contínua e dosada no contexto dos conteúdos das diversas disciplinas.

O conteúdo exposto é conhecimento consolidado de metodologia do ensino superior, mostrando-se atual, pertinente e adequado para utilização na educação superior nestes tempos correntes, os quais trouxeram para os bancos das faculdades alunos com dificuldades socioeconômicas e educacionais de base como nunca antes vistos.

Não obstante a pertinência dessa pedagogia para tais alunos, entende-se que eles, dadas suas dificuldades adicionais, exigem um cuidado especial do Estado, das instituições de ensino e dos professores para permitir o efetivo aproveitamento de seus potenciais.

E aqui entram as várias responsabilidades de cada um dos agentes envolvidos na educação.

Ao Estado cabe propiciar ao aluno bolsas de alimentação, moradia e material didático, de forma que ele não tenha que se preocupar com sua subsistência e condições durante o curso. Caso o Estado falhe, cabe ao docente uma preocupação residual com os alunos que não obtiverem esses meios, notadamente para evitar exigir um tempo de estudos fora de sala muito superior aos limites daqueles que trabalham, mas sem descuidar de evitar nivelar o ensino pelo piso.

À instituição de ensino compete organizar turmas de nivelamento para assegurar aos ingressantes o conhecimento de conteúdos básicos necessários ao curso, os quais deveriam ter sido aprendidos nos anos anteriores, bem como uma estrutura de apoio pedagógico durante o curso para acompanhamento dos casos excepcionais. Importante registrar que as aulas de nivelamento poderão contribuir muito para a qualidade da graduação, sendo de interesse da instituição, posto que a avaliação dos alunos ao fim do curso feita pelo Ministério da Educação refletirá no conceito da instituição.

E, ao professor, cabe um cuidado especial com esses alunos. Sim, porque embora eles tenham uma base educacional deficitária, o seu potencial de aprendizado não é 
inferior. Pesquisas em algumas universidades que adotaram há mais tempo políticas de cotas evidenciam inclusive o contrário, que esses alunos, possuidores de igual potencial, às vezes têm rendimento até superior, tendo em vista a valorização que dão à oportunidade recebida.

Assim, por essa ótica do cuidado, algumas práticas ou técnicas educacionais são recomendáveis, passando-se a expô-las agora.

\subsection{Sugestões pontuais de técnicas ou práticas educacionais}

Recomenda-se, antes de tudo, o conhecimento dos alunos pelo professor, podendo, com esse intuito, utilizar a primeira aula para apresentar-se e conhecê-los um a um. Sem pressa e com respeito, dando a cada um a oportunidade de falar sobre sua trajetória, seus gostos, a razão da escolha do curso, os projetos de futuro e como pretende se dedicar ao curso.

Essa conversa tem muita utilidade e poderá ser muito útil para o planejamento dos conteúdos. Ao mesmo tempo, ambienta o aluno no novo espaço, por vezes incompreendido e assustador, e fortalece os laços dos alunos entre si e com o professor. É um bom começo, uma boa semente lançada que germinará e poderá render uma árvore forte e de bons frutos se a planta for cuidada. O passo seguinte é adotar práticas para motivar os alunos.

Gil (2009, p. 62) recomenda que o professor, após estabelecer uma relação amistosa com os alunos, procure despertar o interesse contínuo dele, podendo, para isso, apresentar o conteúdo de forma a despertar vontade de obter respostas a questões apresentadas e a saber a razão das coisas. Outra técnica consiste em o professor mostrar continuamente a importância da matéria para o aluno e em que ela lhe será útil.

Optou-se por apresentar aqui sugestões autorais, de forma que se reporta o leitor às primorosas sugestões feitas por Gil na obra Metodologia do Ensino Superior de várias técnicas para manter a atenção dos alunos, estimular a reação, fornecer feedback, favorecer a retenção e criar condições para possibilitar a transferência da aprendizagem.

Nessa linha de considerações de natureza autoral, recomenda-se um ensino que foque a realidade do aluno, considerando seu passado, presente e aspirações futuras. Aqui a importância de conhecer a turma e de o professor estar inteiro em seu magistério. O intuito de considerar as aspirações futuras pode ser contemplado com a utilização de casos práticos, desafiando os alunos a resolverem problemas semelhantes aos que enfrentarão na 
prática profissional. As simulações são exemplares para tanto, às quais se pode acrescentar um grande motivador quando realizadas como competições entre grupos. À simulação e à resolução de casos práticos após o estudo da teoria pode-se contrapor o aprendizado da própria teoria por meio do desafio de solução de problemas dados, com as vantagens indicadas.

A limitação de tempo de alguns alunos não pode ser ignorada pelo professor, sob pena de excluir da aprendizagem boa parte da turma.

Esta, a aprendizagem, não é medida pelo volume de informações transmitidas, mas pelo nível de conhecimentos efetivamente absorvidos - não apenas memorizados, mas absorvidos a ponto de o discente ser capaz aplicá-lo e, mais ainda, de transformar o próprio aluno. Assim, é melhor optar-se por menos conteúdo, escolhendo-o com rigoroso critério de relevância e qualidade, e investir em técnicas para maximizar o grau de aprendizado.

Com essa intenção, recomenda-se inclusive a leitura coletiva de pequenos textos em sala de aula, seguida de discussões, sem limitar o conteúdo das aulas a isso, logicamente. É técnica que, a um só tempo, inclui todos os presentes nas discussões e concede a cada um deles a possibilidade de desenvolvimento de sua capacidade de reflexão e de expressão oral, inclusive a partir da leitura do texto em voz alta. Essa é apenas uma das técnicas e não exclui outros conteúdos e a leitura extraclasse. Mas os textos prioritários devem ser selecionados de forma a bem aproveitar o pouco tempo que tem o aluno.

Mas, poder-se-ia perguntar se os alunos que dispõem de mais tempo e potencial de aprendizado acima da média não seriam prejudicados.

A resposta é negativa. O professor deve cuidar para que isso não ocorra. Ao mesmo tempo em priorizaria garantir que a totalidade da turma obtivesse uma aprendizagem efetiva e sólida dos conteúdos essenciais, o mestre disponibilizaria material complementar para todos que tivessem interesse. E, aos que efetivassem as leituras extras, daria um acompanhamento específico fora de sala de aula, disponibilizando-se a esclarecer dúvidas ou orientá-los durante uma ou duas horas por semana em seu gabinete, bem como os desafiando a escrever artigos científicos adicionais.

Esse proceder garante que todos aprendam solidamente os fundamentos básicos e essenciais e que não se nivele por baixo o aprendizado daqueles que têm tempo e potencial acima da média.

Propõe-se, também, uma mudança na forma de avaliação. 
Em vez de poucas avaliações concentradas e que valorizem os aspectos formais, sugere-se que sejam feitas mais avaliações, de forma contínua e próximas dos momentos em que ministrados os conteúdos avaliados. Isso reduz o estresse do estudante e lhe permite preocupar-se mais com seu aprendizado e não com a obtenção de notas.

Além disso, propõe-se, nas avaliações, a desvalorização ou exclusão de aspectos formais e de memorização e a valorização da interpretação construída pelo aluno a partir do aprendizado reflexivo e de sua capacidade de aplicar o aprendido no dia a dia. Ao invés da extensão do textos, que se privilegie o número de ideias e a solidez da argumentação utilizada para sustentá-las, pois é isso que se exige no exercício profissional responsável. Não se ganham causas pelo número de páginas e nem elas, na engenharia, sustentam prédios e pontes.

\section{CONCLUSÕES}

O Brasil vive um momento de massificação no acesso ao ensino superior. Isso ocorre em face do vertiginoso aumento das vagas nos cursos de graduação nas últimas duas décadas, pela compra ou financiamento de vagas pelo poder público em instituições privadas e também pela promulgação da Lei $n^{\circ} 12.711 / 2012$, a lei de cotas nas universidades públicas.

Essa realidade trouxe aos bancos acadêmicos um número nunca antes visto de pessoas com características de fragilidade econômica e educacional, tanto nas instituições privadas como especialmente nas públicas federais em face da aplicação de cotas em todos os cursos para alunos oriundos da escola pública, com recorte adicional segundo a renda e a origem étnica.

A situação exige um cuidado especial do Estado, das instituições de ensino e dos professores, objetivando garantir que esses alunos desenvolver plenamente o seu potencial.

Do Estado, por meio da adoção de políticas sociais que minimizem a preocupação com a subsistência dos alunos carentes durante o curso e que lhes garantam acesso a todo o material didático necessário.

Das instituições de ensino, via estabelecimento de bases curriculares que prevejam aulas de nivelamento no início dos cursos, objetivando assegurar que todos tenham acesso a 
conteúdos mínimos exigidos para a compreensão das matérias próprias da graduação, e pelo fornecimento de suporte pedagógico adicional extraclasse para aqueles que necessitarem.

Dos docentes o que se exige é um maior cuidado no ensino, mediante a aplicação dos conhecimentos pedagógicos existentes.

Não há, porém, necessidade de desenvolvimento de uma nova metodologia do ensino superior. Os suportes teóricos existentes são adequados e suficientes para a nova realidade, exigindo apenas que sejam efetivamente utilizados e que haja comprometimento e sensibilidade por parte dos educadores. Longe de contrariar essa conclusão, as sugestões de práticas foram apenas exemplos fundados no conhecimento já existente, sem negá-lo ou evidenciar eventual falência.

Em síntese, a metodologia do ensino permanece válida e não há necessidade de ruptura com a criação de uma nova metodologia. Está sujeita a aperfeiçoamentos e a evolução, que são naturais, mas a situação atual do ensino superior no Brasil não evidencia sua negação com criação de nova metodologia.

\section{REFERÊNCIAS BIBLIOGRÁFICAS}

AGRA, Walber de Moura. Curso de Direito Constitucional. 8. ed. Rio de Janeiro: Forense, 2014.

BRASIL. Lei $\mathrm{n}^{\mathrm{o}}$ 12.711, de 29 de agosto de 2012. Disponível em:

<http://www.planalto.gov.br/ccivil_03/1_ato2011-2014/2012/lei/112711.htm>. Acesso em: 10 ago. 2015.

CONCEIÇÃO, Noslean Silva Duarte da. Ensino Jurídico: um olhar da pedagogia sobre a prática brasileira. Monografia (Trabalho de Conclusão de Curso). Brasília: UniCEUB, 2014.

GIL, Antonio Carlos. Metodologia do ensino superior. 4. ed. São Paulo: Atlas, 2009.

ECO, Humberto. Como se faz uma tese. Trad. Gilson Cesar Cardoso de Souza. 14. ed. São Paulo: Perspectiva, 1998.

INSTITUTO BRASILEIRO DE GEOGRAFIA E ESTATÍSTICA- IBGE. Estimativa de população. Disponível em: 
<http://www.ibge.gov.br/home/estatistica/populacao/estimativa2014/serie_2001_2014_tcu. sht m>. Acesso em: 16 ago. 2015.

.Estatísticas de população. Disponível em: <http://memoria.ibge.gov.br/sinteseshistoricas/historicos-dos-censos/censos-demograficos.html>. Acesso em: 16 ago. 2015.

INSTITUTO NACIONAL DE ESTUDOS E PESQUISAS EDUCACIONAIS ANÍSIO TEIXEIRA - INEP. Sinopse Estatística do Ensino Superior. Disponível em:

<http://portal.inep.gov.br/superior-censosuperior-sinopse>. Acesso em: 16 ago. 2015.

MACÊDO, Márcia Andréa Durão de. Cotas raciais nas universidades brasileiras. Legalização da discriminação. Disponível em: <http://jus.com.br/artigos/13491/cotasraciais-nas-universidades-brasileiras>. Acesso em: 24 ago. 2015.

PESSOA, Flávia Moreira Guimarães (Org.). Reflexões sobre a docência jurídica. Série Estudos de Metodologia. Vol. 1. Aracaju: Evocati, 2013.

; ANDRADE, Layanna Maria Santiago. Por um novo método no ensino jurídico. In: PESSOA, Flávia Moreira Guimarães (org.). Reflexões sobre a docência jurídica. Série Estudos de Metodologia. Volume 1. Aracaju: Evocati, 2013.

ROCHA, J.V.S. Ensino jurídico transformador. Umuarama: Rev. Ciênc. Jur. e Soc. Da Unipar, v. 10, nº 1, p. 185-198, 2007.

SANTOS, Rute Gomes dos. Metodologia do ensino superior: o papel da didática na articulação entre saber e prática docente, numa perspectiva pedagógica-epistemológica. Dissertação (Mestrado). Florianópolis: Universidade Federal de Santa Catarina, 2001. 